\title{
Subgenera of Charidotella Weise with description of a new subgenus and species from Brazil (Coleoptera, Chrysomelidae, Cassidinae, Cassidini)
}

\author{
Lukáš Sekerka ${ }^{1,2}$, Lech Borowiec ${ }^{3}$ \\ I Department of Entomology, National Museum, Cirkusová 1740, CZ-193 00 Praha 9, Czech Republic \\ 2 Department of Zoology, Faculty of Science, University of South Bohemia, Branišovská 31, CZ-370 05 České \\ Budějovice, Czech Republic 3 Department of Biodiversity and Evolutionary Taxonomy, University of Wroctaw, \\ Przybyszewskiego 63/77, 51-148 Wroctaw, Poland
}

Corresponding author: Lukášs Sekerka (sagrinae@seznam.cz)

Academic editor: A. Konstantinov | Received 17 October 2014 | Accepted 11 May 2015 | Published 28 May 2015

http://zoobank.org/BD777FC2-6CB8-43B7-AE34-2FBFEC620025

Citation: Sekerka L, Borowiec L (2015) Subgenera of Charidotella Weise with description of a new subgenus and species from Brazil (Coleoptera, Chrysomelidae, Cassidinae, Cassidini). ZooKeys 506: 61-74. doi: 10.3897/zookeys.506.8770

\begin{abstract}
A new subgenus and species, Charidotella (Chapadacassis subgen. n.) paradoxa sp. n. is described and figured from the Chapada plateau in Mato Grosso, Brazil. Subgenera of Charidotella Weise, 1896 are listed, supplemented with basic data, diagnostic table, and a key is proposed. Based on a study of respective type material following new combinations are proposed: Charidotella (Philaspis) stulta (Boheman, 1855), comb. n., Charidotella (Xenocassis) amoenula (Boheman, 1855), comb. n., Ch. (X.) cyclographa (Boheman, 1855), comb. n., Ch. (X.) discoidalis (Boheman, 1855), comb. n., Ch. (X.) incerta (Boheman, 1855), comb. n., Ch. (X.) purpurea (Linnaeus, 1758), comb. n., Ch. (X.) myops (Boheman, 1855), comb. n. (all previously placed in the nominotypical subgenus), and Plagiometriona cingulata (Boheman, 1862), comb. n. (from Charidotella (Xenocassis)).
\end{abstract}

\section{Keywords}

Entomology, taxonomy, new subgenus, new species, new combination, Neotropical Region, Brazil 


\section{Introduction}

New World Cassidini comprises currently 726 species in 46 genera. Brazil is the country with richest fauna represented by 402 species, 252 of them so far known only from Brazil (Borowiec and Świętojańska 2015). Most likely the number of endemic taxa will be much lower as many species occur also in neighbouring countries. Particularly Bolivia and Venezuela are quite poorly explored regarding Cassidinae fauna and our recent research indicates that many species so far known only from Brazil are present in these countries too (Windsor and Sekerka, unpubl. data).

Dry regions of Southern America are poorly collected and many species are known only from small areas while their range is in fact large. This is particularly true for western Bolivia and central-west Brazil (Windsor and Sekerka, unpubl. data). The Chapada plateau in Mato Grosso is perhaps one of the most interesting areas in this part of Southern America and probably hides numerous undescribed taxa. Several cassidines were described recently by Świętojańska and Borowiec (1995, 1996, 1999) and Borowiec (2004). In the material studied recently we found a new species belonging to an undescribed peculiar subgenus of Charidotella Weise, 1896 characterized by completely irregular punctation of the elytra, a very rare morphological feature in $\mathrm{New}$ World Cassidini.

Weise (1896) proposed Charidotella for a single species, Ch. zona (Fabricius, 1801), while he also created Metriona Weise, 1896 where he placed most species currently classified in Charidotella. Spaeth (1914) downgraded Charidotella to subgenus of Metriona and designated M. elatior (Klug, 1829) as the type species of the latter. He also included six more species in Charidotella, all having pattern on the ventral side of the elytral disc. Spaeth (1942) raised Charidotella to genus rank and listed eleven species in it. Meantime, Spaeth described several genera (Philaspis Spaeth, 1913, Xenocassis Spaeth, 1936 and Metrionaspis Spaeth, 1942) for species previously classified in Coptocycla Chevrolat, 1836 or Metriona. Subsequently Hincks (1952) placed them as subgenera of Charidotella and validated one more subgenus Charerocassis Spaeth in Hincks, 1952 following Spaeth's unpublished manuscript for Wytsman's Genera Insectorum. Borowiec (1989) placed Metrionaspis as subgenus of Charidotella, proposed a key to the subgenera and the first catalogue of the genus. Most recently, Windsor et al. (1992) considered Xenocassis as a separate genus, however, this change was not accepted and Xenocassis remained as subgenus of Charidotella (e.g. Borowiec 1999).

Currently Charidotella comprises 100 species divided in five subgenera (Borowiec and Świętojańska 2015). Identification of subgenera was established mainly on the basis of structure of tarsal claws (simple vs. appendiculate) by Spaeth (1936) and followed by Borowiec (1989). General body shape, convexity of the elytra, and punctation provide good characters too, however, in many cases they are hard to describe to be clearly and easily understood. The structure of tarsal claws proved as yet not fully understood and at least some species have intraspecific variability in presence or absence of the basal tooth on respective claw (e.g. Riley 1982, 1986). Besides the key we provide also a diagnostic table (Table 1) to help to recognize subgenera of Charidotella. 


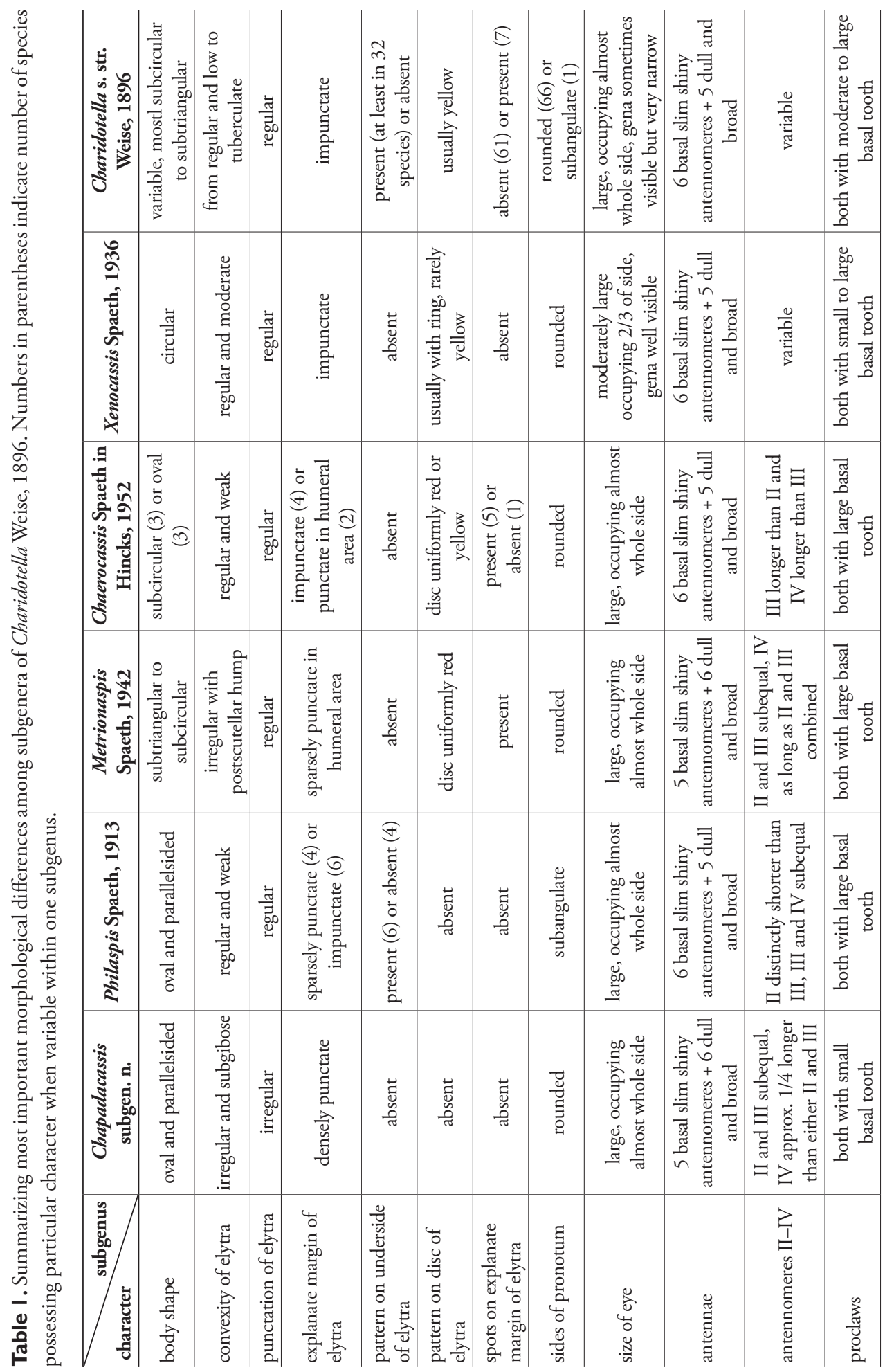




\begin{tabular}{|c|c|c|}
\hline 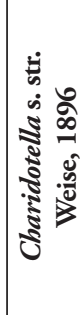 & 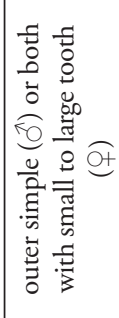 & 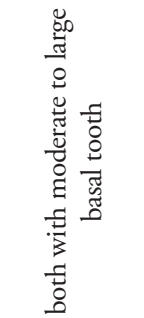 \\
\hline 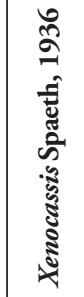 & 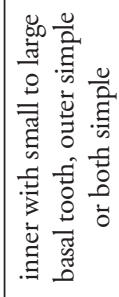 & 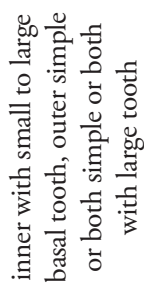 \\
\hline 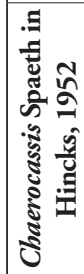 & 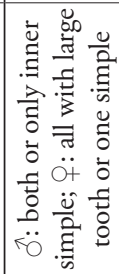 & 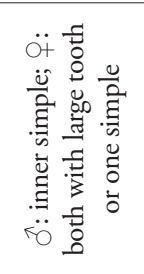 \\
\hline 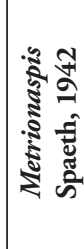 & 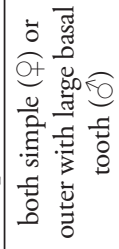 & 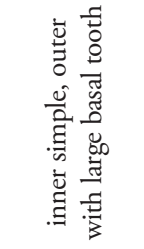 \\
\hline 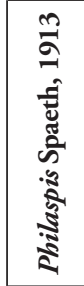 & 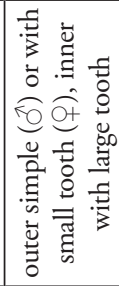 & 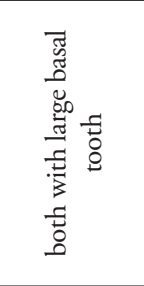 \\
\hline 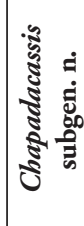 & 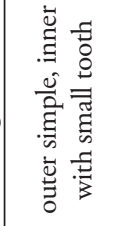 & 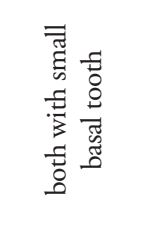 \\
\hline 苟 & 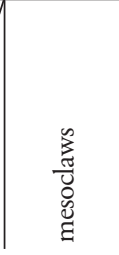 & 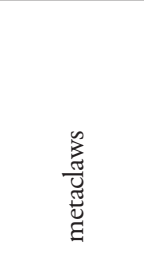 \\
\hline
\end{tabular}


The genus Charidotella can be characterized by at least some tarsal claws with a basal tooth, venter of the pronotum without antennal grooves, the clypeus flat or impressed and without distinct grooves, and a broad prosternal process with the apex not strongly expanded laterally. Charidotella species are mostly associated with the plant family Convolvulaceae, mainly with the diverse genus Ipomoea, however at least one species is associated with Asteraceae (Windsor and Sekerka, unpubl. data).

Label data from the type specimens are cited as they appeared on the labels. Individual labels are separated by a double vertical bar "I" and rows within the label by a single vertical bar "|".

\section{Overview of subgenera of Charidotella}

\section{Charidotella (s. str.) Weise, 1896}

Figs 8-9

Charidotella Weise, 1896: 13.

Type species. Cassida zona Fabricius, 1801 by monotypy.

Number of species. 67 (Borowiec and Świętojańska 2015, present paper).

Key to species. Borowiec (2007) proposed a key covering 23 species with pattern on the ventral part of the elytral disc.

Range. Canada to Argentina.

Distinguishing characters. Species of the nominotypical subgenus can be separated by all tarsal claws with a basal tooth of variable size, or in males the outer claw of mesotarsi is with small tooth or simple. They also have subcircular to subtriangular body and are more convex in comparison to most other subgenera except Metrionaspis and Chapadacassis subgen. n. Otherwise the nominotypical subgenus is polymorphic displaying greater variability and some species externally reminds other subgenera. Most species are yellow with or without pattern on the ventral side of the elytral disc which can be variable. After revising most species of Charidotella there is no species in the nominotypical subgenus with dark annulus on the upper side of the elytra and all such coloured species are here transferred to Xenocassis.

\section{Chaerocassis Spaeth in Hincks, 1952}

Figs $10-11$

Charidotella subgen. Chaerocassis Spaeth in Hincks, 1952: 350.

Type species. Coptocycla marculenta Boheman, 1855 by original designation.

Number of species. 6 (Borowiec and Świętojańska 2015).

Key to species. Not yet proposed. 
Range. USA to Panama.

Distinguishing characters. Chaerocassis species have subcircular or oval body outline, regularly convex elytra, the base of the elytra distinctly wider than the pronotum and humeral angles moderately projecting anterad. Four species have explanate margin of the elytra with basal and posterolateral spots. One species has outer margin of the elytra black and the type species is uniformly yellow. Males have the outer claw of meso- and metatarsi, or both claws of meso- and the outer claw of metatarsi simple. Females have all claws appendiculate or one of the meso- and metatarsi simple. They are externally close to the nominotypical subgenus but can be easily separated by one of the metaclaws simple and elytra always without pattern on uderside.

\section{Metrionaspis Spaeth, 1942}

Figs 16-17

Metrionaspis Spaeth, 1942: 39; Borowiec 1989: 204 (as subgenus of Charidotella).

Type species. Aspidomorpha rubicunda Guérin-Méneville, 1844 by monotypy.

Number of species. 2 (Borowiec and Świętojańska 2015).

Key to species. Not yet proposed.

Range. Charidotella rubicunda is widely distributed through South America from Colombia to Argentina while Ch. santaremi Borowiec, 1995 is so far known only from the state of Pará in Brazil.

Distinguishing characters. The two Metrionaspis species have a broadly oval to subtriangular body outline, base of the elytra distinctly wider than pronotum with humeral angles projecting anterad, explanate margin of the elytra with humeral and posterolateral spots, and the elytra with a postscutellar tubercle. Externally both species are very similar to two Charidotella s. str. species, Ch. tuberculata (Fabricius, 1775) and Ch. ventricosa (Boheman, 1855), but they can be separated by an impunctate explanate margin of the elytra and claws of the metatarsi in both sexes with a basal tooth. While Metrionaspis species have humeral area of the explanate margin punctate and the inner claw of the metatarsi simple in both sexes.

\section{Philaspis Spaeth, 1913}

Figs 14-15

Philaspis Spaeth, 1913: 142; Hincks 1952: 342 (as subgenus of Charidotella).

Type species. Odontionycha seriatopunctata Spaeth, 1901 designated by Hincks (1952).

Number of species. 10 (Borowiec 2004, present paper).

Key to species. Spaeth (1936) covered eight species, Borowiec (2004) covered nine species. 
Range. One species in Mexico and Costa Rica, remaining in the southern part of South America.

Distinguishing characters. Philaspis species are at first glance easily distinguished by the parallel-sided elytra in combination with subangulate sides of the pronotum. All species are uniformly yellow or have a small black spot in the middle of each elytron.

Remarks. Charidotella stulta (Boheman, 1855) was previously classified in the nominotypical subgenus. We recently examined its holotype, preserved in Museum für Naturkunde, Berlin, and found that it belongs to the subgenus Philaspis near Ch. (P.) inculta (Boheman, 1855).

\section{Xenocassis Spaeth, 1936}

Figs 12-13

Xenocassis Spaeth, 1936: 260; Hincks 1952: 342 (as subgenus of Charidotella).

Type species. Coptocycla amoena Boheman, 1855 by original designation.

Number of species. 15 (present paper).

Key to species. Not yet proposed.

Range. Mexico to Peru with most species in the Central America.

Distinguishing characters. Xenocassis species can be easily separated from other subgenera by the small eyes covering only $2 / 3$ of lateral sides of the head thus gena is well visible while all other subgenera have large eyes. In addition Xenocassis has nearly regularly circular body outline, weakly convex elytra with coarser punctation on lateral slope, and dorsum with ring pattern on the upper side. In extreme cases the ring can form a large discal spot or can be completely vanished thus whole dorsum is uniformly yellow.

Remarks. So far Xenocassis was separated from other genera on the basis of the tarsal claws and general body shape. Windsor et al. (1992) were the first who noticed that all species have also small eyes in comparison to other Chardotella species. As a result they raised Xenocassis to genus in the provided key but unfortunately made no additional comments and their change was not accepted later (e.g. Borowiec 1999). We agree with them that the small size of the eye is diagnostic for Xenocassis and found that five species currently classified in the nominotypical subgenus should be transferred to Xenocassis based on this character. In addition we found that Xenocassis species are very variable regarding the size and presence of tarsal appendages. The genus was based by Spaeth (1936) on the outer claws of the metatarsi simple in both sexes, however, examination of extensive material revealed that even the type species, $C$. amoena, could have the outer claws of the metatarsi with a large basal tooth. Similar situation was found in two other species we had extensive material to study - Ch. (X.) ambita (Champion, 1894) and Ch. (X.) puella (Boheman, 1855). In both the basal teeth showed variable size even within one population. While the size of the eye is constant. Some species of other subgenera have slightly smaller eyes than others thus they have gena visible but always very narrow while species of Xenocassis have gena covering approximately basal third of lateral side of the head. 
We consider Xenocassis as subgenus of Charidotella as the size of the eye is found variable also in some other new world Cassidini genera, e.g. Charidotis Boheman, 1855 and Plagiometriona Spaeth, 1899.

Last catalogue, Borowiec (1999) listed 10 species in the subgenus Xenocassis. We have recently examined types of all species and found that one was wrongly assigned to Xenocassis. Coptocycla cingulata Boheman, 1862 (type seen in the Natural History Museum, London) was unknown to most authors and have been tentatively placed in Charidotella based on the original description (Boheman 1862) and notes published by Champion (1894) in the Cassidinae volume of the Biologia Centrali Americana (Borowiec 1989). It posses all characters of the genus Plagiometriona and is here transferred to it as Plagiometriona cingulata (Boheman, 1862), comb. n.

During examination of species placed in the nominotypical subgenus we found four which had small eyes and are here transferred to Xenocassis: Ch. (X.) discoidalis (Boheman, 1855), comb. n., Ch. (X.) incerta (Boheman, 1855), comb. n., Ch. (X.) purpurea (Linnaeus, 1758), comb. n., and Ch. (X.) myops (Boheman, 1855), comb. n. Types of all, with exception of $C h$. purpurea, were examined and are preserved in the Naturhistoriska Riksmuseet, Stockholm, Sweden. In addition Boheman (1855) described two more species in the same groups as abovementioned ones and we have strong feeling that they belong to Xenocassis too: Ch. (X.) amoenula (Boheman, 1855), comb. n. and Ch. (X.) cyclographa (Boheman, 1855), comb. n. Unfortunately, we were not able to locate their type specimens thus the transfer is tentative, based on primary descriptions according to which the species should have the circular body shape, the annulus on upper side of the elytra, and coarser punctation on the lateral slope of elytral disc like other Xenocassis species.

\section{Chapadacassis subgen. $\mathbf{n}$.}

http://zoobank.org/2BC3A84F-44A2-48C0-A888-14EB4101B789

Figs 1-7

Type species. Charidotella (Chapadacassis) paradoxa sp. n. here designated.

Etymology. The genus name is a combination of its type locality, the Chapada plateau and the genus name Cassida, gender feminine.

Diagnosis. Chapadacassis subgen. $\mathrm{n}$. is well characterized by completely irregular punctation of the elytra, only apical two thirds of sutural row appear more or less regular, while all other Charidotella species have mostly regular punctation of the elytra. Mostly or completely irregular punctation of the elytra is generally a rare feature in Neotropical Cassidini present only in a few taxa (e.g. Metriona elatior (Klug, 1829) or Scaeocassis turbulenta (Boheman, 1862)).

Externally, Chapadacassis subgen. $\mathrm{n}$. is reminiscent of Philaspis because of the body shape, but Philaspis species have moderately and regularly convex elytra without any impressions while Chapadacassis subgen. $\mathrm{n}$. has strongly convex elytra with moderate scutellar impressions thus elytral profile is distinctly broken (Fig. 2). Chapadacassis subgen. n. also differs in having lateral sides of pronotum rounded (angulate in Philaspis), tarsal 

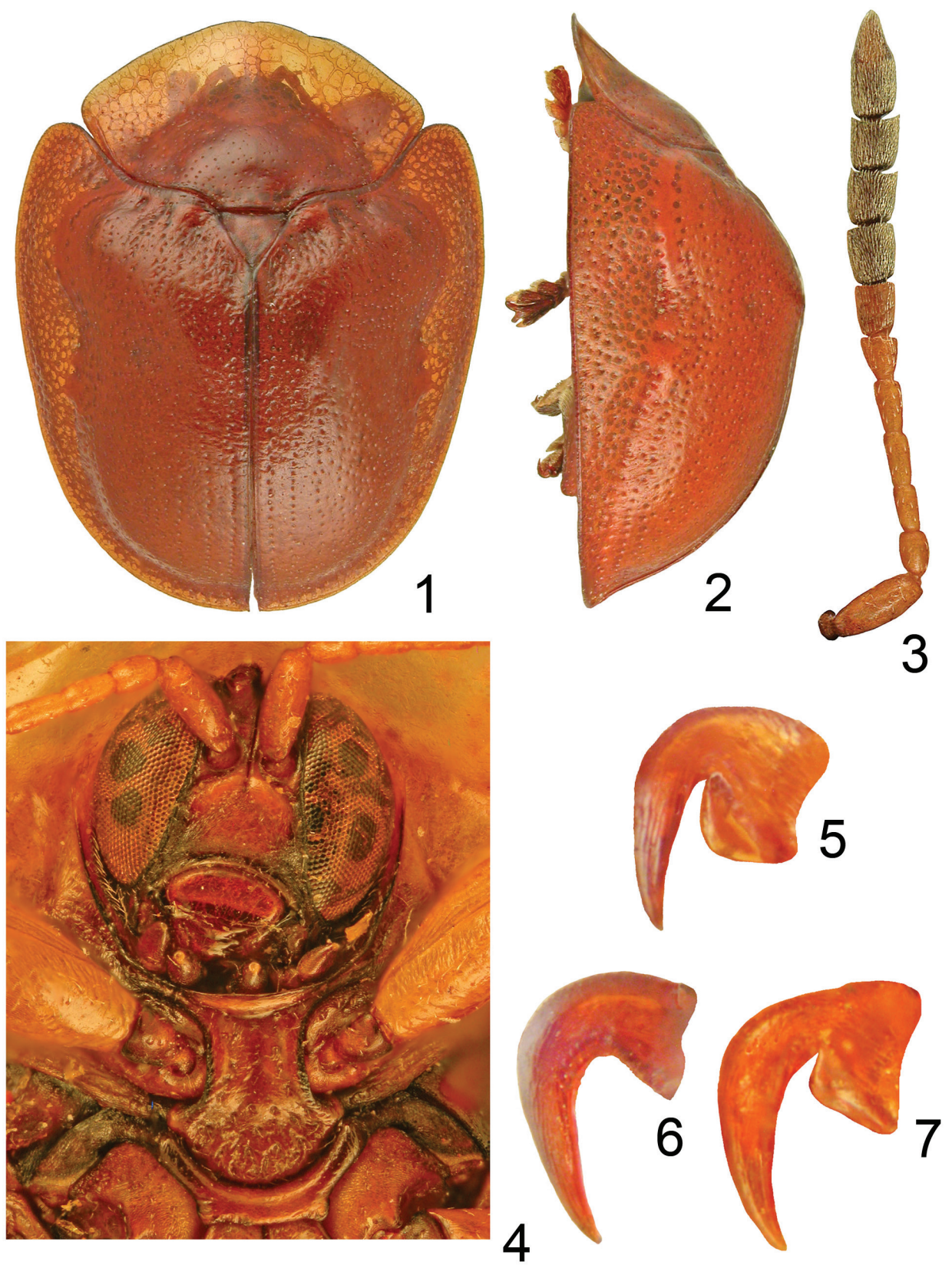

Figures I-7. Charidotella (Chapadacassis) paradoxa sp. n. I body dorsal $\mathbf{2}$ body lateral $\mathbf{3}$ antenna $\mathbf{4}$ head and prosternum $\mathbf{5}$ outer claw of protarsus $\mathbf{6}$ inner claw of mesotarsus $\mathbf{7}$ inner claw of metatarsus.

claws with small tooth (large in Philaspis), antennae with five basal shiny and slim antennomeres (six in Philaspis), and antennomeres II and III subequal in length and IV longer than either (III and IV subequal in length and II distinctly shorter than either one). 


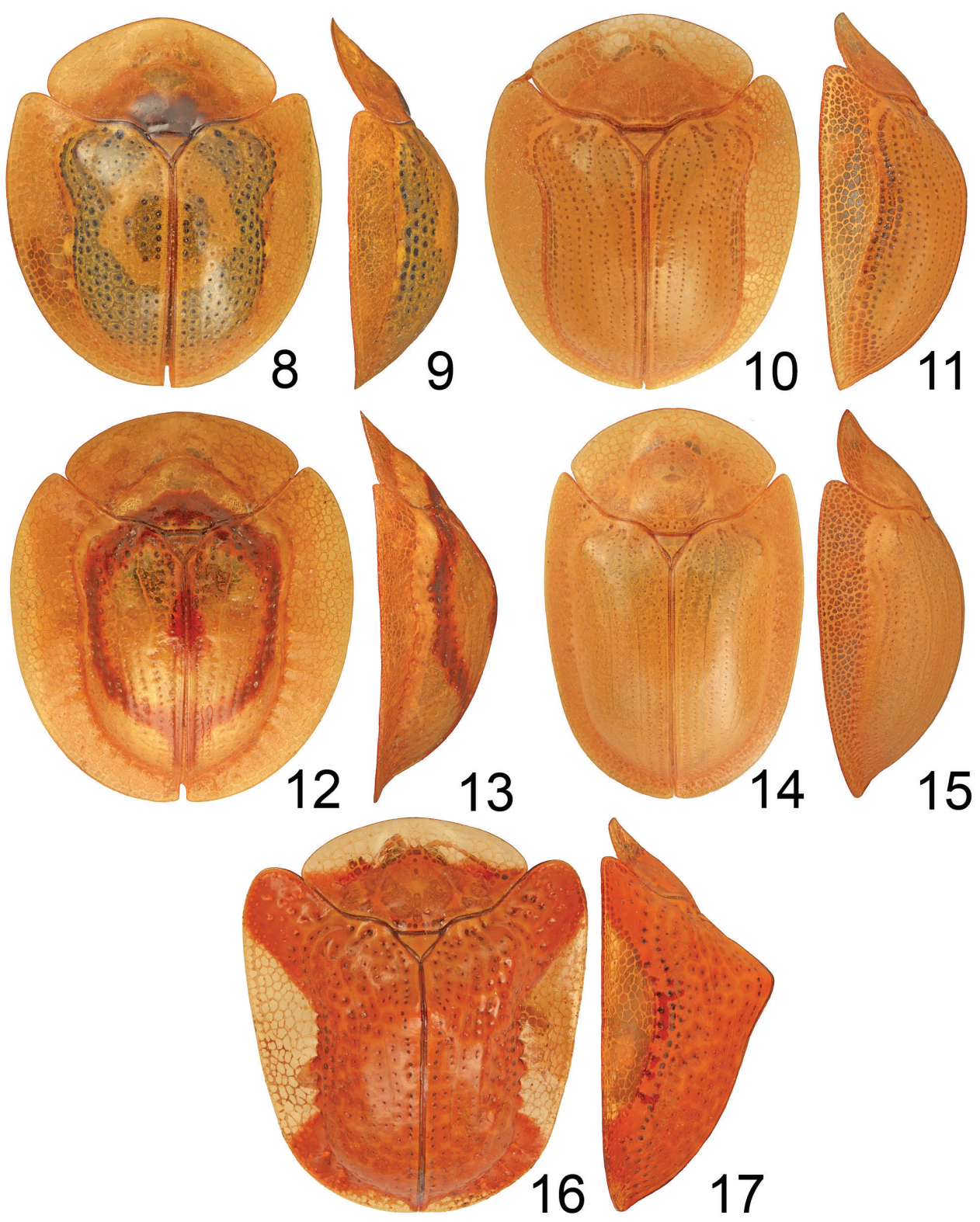

Figures 8-17. Type species for subgenera of Charidotella. 8-9 Charidotella (s. str.) zona (Fabricius, 1801) I 0-I I Charidotella (Chaerocassis) marculenta (Boheman, 1855) I2-13 Charidotella (Xenocassis) amoena (Boheman, 1855) I4-I5 Charidotella (Philaspis) seriatopunctata (Spaeth, 1901) I6-I7 Charidotella (Metrionaspis) rubicunda (Guérin-Méneville, 1844).

Description. Body $7.6 \mathrm{~mm}$ long and $5.9 \mathrm{~mm}$ wide, broadly oval and strongly convex (Figs 1-2). Pronotum subpentagonal, 1.9 times wider than long, widest slightly before midlength with obtuse lateral sides. Disc indistinctly separated from explanate 
margin, whole surface of pronotum sparsely and coarsely punctate. Scutellum triangular, smooth, dull, micro-reticulate. Elytral base distinctly wider than base of pronotum, humeral angles strongly protruding anterad and rounded. Disc strongly convex, moderately impresed on each side of scutellum, thus lateral profile broken (Fig. 2). Punctation of elytra overall coarse, mostly irregular only first two rows more or less regular in apical half. Marginal row distinct, interrupted by large callosity around midlength, its punctures approximately twice coarser than those on disc. Explanate margin broad, almost as broad as half width of disc, strongly declivous, sparsely and coarsely punctate. Extreme outer margin swollen.

Eyes large, gena not visible. Clypeus transverse, impunctate and shiny, anterior margin micro-rugose and slightly elevated (Fig. 4). Antennae slim, antennomeres I-V slim, glabrous and shiny, antennomere V intermediate, VI-XI broad and densely pubescent (Fig. 3). Labrum oval, not emarginate. Mandible with three large teeth. Prosternal collar slightly expanded towards mouth. Prosternal process broad with moderately expanded apex. Metepisterna coarsely punctate and dull. Mesepimera and mesepisterna micro-reticulate and dull. Metaventrite smooth, shiny and sparsely punctate. Abdominal ventrites I-IV smooth and shiny, V shiny and sparsely punctate, each puncture with long seta. Legs normal, slim, tarsal claws divergent. Both pro- and metaclaws appendiculate with small tooth. Outer mesoclaw claw simple (Fig. 6), inner with small tooth.

\section{Charidotella (Chapadacassis) paradoxa sp. $\mathbf{n}$.}

http://zoobank.org/2F581A64-5A62-4D6C-BDBA-0570F65417EA

Type locality. The type locality most likely refers to Chapada dos Guimarães (approximately $\left.15^{\circ} 10^{\prime}-15^{\circ} 30^{\prime} \mathrm{S}, 55^{\circ} 40^{\prime}-56^{\circ} 00^{\prime} \mathrm{W}\right)$, Mato Grosso, Brazil.

Type material. Holotype, pinned: "BRAZIL, Mato Grosso | Chapada Plateau | XI 1965 | native collector [white, printed and cardboard label]" (preserved at Department of Biodiversity and Evolutionary Taxonomy, Wrocław, Poland). Paratype, pinned: same data as holotype (preserved in collection of L. Sekerka, Prague, Czech Republic). Both specimens are provided with an additional red, printed and cardboard label: "HOLOTYPUS [or PARATYPUS respectively] | Charidotella | Chapadacassis sgen. n. | paradoxa sp. n. | L. Sekerka \& | L. Borowiec des. 2014".

Description. Body $7.6 \times 5.9 \mathrm{~mm}$, broadly oval and strongly convex (Figs 1-2).

Dorsum uniformly reddish-yellow. Margins of thoracic segments, trochanters, head, central parts of abdominal ventrites, and tarsi infuscate. Remaining ventral parts yellow. Five terminal antennomeres black, remaining yellow.

Pronotum subpentagonal, 1.9 times wider than long, widest slightly before midlength with obtuse lateral sides. Disc indistinctly separated from explanate margin, strongly convex, without impressions, sparsely and coarsely punctate, punctures laterobasally gradually coarser. Interspaces smooth and shiny, 1-4 times wider than puncture diameter. Explanate margin broad, lateral sides coarsely and sparsely punc- 
tate, transparent, smooth, and shiny, and with honeycomb structure. Anterior margin regularly convex.

Scutellum triangular, smooth, dull, micro-reticulate.

Elytra widest in basal third, then slowly tapering posteriorly. Elytral base distinctly broader than base of pronotum, humeral angles strongly protruding anterad and rounded. Disc strongly convex, with moderate impression on each side of scutellum, thus profile broken in lateral view (Fig. 2). Punctation of elytra overall coarse, mostly irregular only first two rows more or less regular in apical half. Punctures gradually coarser from top of disc to lateral sides. Interspaces 1-5 times wider than puncture diameter, finely micro-reticulate and appear shiny. Marginal row distinct, interrupted by large callosity around midlength, its punctures approximately twice coarser than those on disc (Fig. 2). Explanate margin broad, almost as broad as half width of disc, strongly declivous, sparsely and coarsely punctate, punctures gradually denser towards base and apex. Interspaces 1-5 times wider than puncture diameter, micro-reticulate and appear dull. Extreme outer margin swollen.

Clypeus 1.3 times broader than long, impunctate and shiny, anterior margin microrugose and slightly elevated. Antennae slim, length ratio of antennomeres: 100:46:49 :59:54:45:57:57:55:56:115. Antennomere III slightly longer than II, VII-X subequal in length and approximately as long as wide (Fig. 3). Labrum oval, its lower margin smooth, not emarginate. Prosternal collar slightly expanded towards mouth. Prosternal process broad with moderately expanded apex, its surface microreticulate, sparsely and coarsely punctate, each puncture with single long seta (Fig. 4).

Legs normal, slim, tarsal claws divergent. Both fore claws appendiculate (Fig. 5). Inner mid claw simple (Fig. 6), outer with small tooth. Inner hind claw with large tooth (Fig. 7), outer with small.

Diagnosis. At first glance Ch. (C.) paradoxa sp. n. reminds some species of the subgenus Philaspis. Particularly recently described, Ch. (P.) marginepunctata Borowiec, 2004 (also from Chapada in Mato Grosso) because of quite similar body shape and coarsely punctate explanate margin of elytra and pronotum. The latter distinctly differs in regularly punctate and less convex elytra without postscutellar impressions, subhorizontal explanate margin of the elytra, and the presence of a small black spot on each elytron.

Etymology. The species epithet from Latin "paradoxus" = peculiar or curious for its unusual combination of morphological characters for Neotropical Cassidini.

Distribution. Brazil (Mato Grosso).

\section{Key to subgenera of Charidotella Weise, 1896}

1 Eyes large covering whole sides of the head, gena very narrow or invisible ....2

- $\quad$ Eyes moderately sized, covering 2/3 of lateral sides of the head, gena well visible, covering the basal third Xenocassis Spaeth, 1936

2 Punctation of elytra regular... 3

- Punctation of elytra completely irregular Chapadacassis subgen. $n$. 
3 Body outline subcircular to subtriangular. Pronotal sides usually broadly

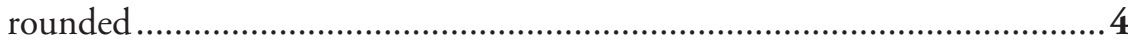

- $\quad$ Body outline oval, parallel-sided. Pronotal sides sub-angulate

$4 \quad$ At least in male one of the metaclaws simple.

Philaspis Spaeth, 1913

All claws in both sexes with basal tooth or in male external claw of mesotarsi simple......

Charidotella s. str.

5 Elytra regularly convex or slightly impressed around scutellum. Antennae with six shiny basal antennomeres and five dull and broad apical.

Chaerocassis Spaeth in Hincks, 1952

- $\quad$ Elytra with a large postscutellar gibbosity, thus lateral profile appears angulate. Antennae with five shiny basal antennomeres and six dull and broad apical

Metrionaspis Spaeth, 1942

\section{Acknowledgements}

We would like to express our sincere thanks to Max Barclay (Natural History Museum, London, UK), Johannes Bergsten (Naturhistoriska Riksmuseet, Stockholm), and Johannes Frisch (Museum für Naturkunde, Berlin, Germany) for their support during study of the collections. Reviewers are acknowledged for valuable comments and suggestions improving the manuscript. Examination of studied type material was supported by the Synthesys programme of the European Union: Natural History Museum, London, UK (GB-TAF-3616), Naturhistoriska Riksmuseet, Stockholm, Sweden (SETAF-3623), and Museum für Naturkunde, Berlin, Germany (DE-TAF-3898). The work was partly financially supported by Ministry of Culture of the Czech Republic (DKRVO 2015/14, National Museum, 00023272).

\section{References}

Boheman CH (1855) Monographia Cassididarum. Tomus Tertius. Officina Norstedtiana, Holmiae, 543 pp.

Boheman CH (1862) Monographia Cassididarum. Tomus Quartus. (Supplementum). Officina Norstedtiana, Holmiae, 504 pp.

Borowiec L (1989) Three new species of Charidotella Weise (Coleoptera, Chrysomelidae, Cassidinae), with checklist of the genus. Polskie Pismo Entomologiczne 59: 203-222.

Borowiec L (1999) A world catalogue of the Cassidinae (Coleoptera: Chrysomelidae). Biologica Silesiae, Wrocław, 476 pp.

Borowiec L (2004) Charidotella (Philaspis) marginepunctata, a new species from Brazil (Coleoptera: Chrysomelidae: Cassidinae). Genus 15(2): 253-256.

Borowiec L (2007) Two new species of Charidotella Weise (Coleoptera: Chrysomelidae: Cassidinae: Cassidini), with a key to Charidotella sexpunctata group. Zootaxa 1586: 59-66. 
Borowiec L, Świętojańska J (2015) Cassidinae of the world - an interactive manual (Coleoptera: Chrysomelidae). Permanent electronic publication available from: http://culex.biol. uni.wroc.pl/cassidae/katalog\%20internetowy/index.htm [accessed 12 April 2015]

Champion GC (1894) [Cassidae]. In: Godman FD, Salvin O (Eds) Biologia CentraliAmericana. Insecta. Coleoptera. Vol. VI. Part 2. Phytophaga (part). Taylor \& Francis, London, 165-232.

Hincks WD (1952) The Genera of the Cassidinae (Coleoptera: Chrysomelidae). Transactions of the Royal Entomological Society of London 103(10): 327-358. doi: 10.1111/j.13652311.1952.tb01061.x

Riley EG (1982) Erepsocassis Spaeth, 1936: a valid genus (Coleoptera: Chrysomelidae: Cassidinae). Journal of the Kansas Entomological Society 55(4): 651-657.

Riley EG (1986) Review of the tortoise beetle genera of the tribe Cassidini occurring in America north of Mexico (Coleoptera: Chrysomelidae: Cassidinae). Journal of the New York Entomological Society 94(1): 98-114.

Spaeth F (1914) Chrysomelidae: 16. Cassidinae. In: Schenkling S (Ed.) Coleopterorum Catalogus, Pars 62. W. Junk, Berlin, 180 pp.

Spaeth F (1936) Mitteilungen über neue oder bemerkenswerte Cassidinen aus dem SenckenbergMuseum (Ins. Col.). Entomologische Rundschau 53(19): 259-262.

Spaeth F (1942) Cassidinae (Col. Chrysom.). In: Titschack E (Ed.) Beiträge zur Fauna Perus, Band II. Gustav Fischer, Jena, 11-43.

Świętojańska J, Borowiec L (1995) Two new species of Microctenochira Spaeth from Brazil and Peru. Genus 6(3-4): 447-454.

Świętojańska J, Borowiec L (1996) A new species of Bradycassis Spaeth from Brazil. Genus 7(3): 471-474.

Świętojańska J, Borowiec L (1999) Three new species of Microctenochira Spaeth from Brazil and Panama. Genus 10(1): 109-116.

Weise J (1896) Feststellung einiger Cassiden-Gattungen. Deutsche Entomologische Zeitschrift 1896(1): 10-15.

Windsor DM, Riley EG, Stockwell HP (1992) An introduction to the biology and systematics of Panamanian totroise beetles (Coleoptera: Chrysomelidae: Cassidinae). In: Quintero D, Aiello A (Eds) Insects of Panama and Mesoamerica, selected studies. Oxford University Press, Oxford-New York-Tokyo, 372-391. 